OPEN ACCESS

Edited by:

Itamar Ronen,

Leiden University, Netherlands

Reviewed by:

Andres Ortiz,

University of Málaga, Spain Konstantinos Kalafatakis, University of Bristol, UK

*Correspondence:

Jan Kassubek

jan.kassubek@uni-ulm.de

Specialty section:

This article was submitted

to Applied Neuroimaging,

a section of the journal

Frontiers in Neurology

Received: 15 March 2017 Accepted: 24 April 2017

Published: 10 May 2017

Citation:

Gorges M, Roselli F, Müller H-P,

Ludolph AC, Rasche $V$ and

Kassubek J (2017) Functional

Connectivity Mapping in the Animal

Model: Principles and Applications of

Resting-State fMRI.

Front. Neurol. 8:200.

doi: 10.3389/fneur.2017.00200

\section{Functional Connectivity Mapping in the Animal Model: Principles and Applications of Resting-State fMRI}

\author{
Martin Gorges ${ }^{1}$, Francesco Roselli ${ }^{1,2}$, Hans-Peter Müller ${ }^{1}$, Albert C. Ludolph', \\ Volker Rasche ${ }^{3}$ and Jan Kassubek ${ }^{1 *}$ \\ ${ }^{1}$ Department of Neurology, University of Ulm, Ulm, Germany, ${ }^{2}$ Department of Anatomy and Cell Biology, University of Ulm, \\ UIm, Germany, ${ }^{3}$ Core Facility Small Animal MRI, University of UIm, UIm, Germany
}

"Resting-state" fMRI has substantially contributed to the understanding of human and non-human functional brain organization by the analysis of correlated patterns in spontaneous activity within dedicated brain systems. Spontaneous neural activity is indirectly measured from the blood oxygenation level-dependent signal as acquired by echo planar imaging, when subjects quietly "resting" in the scanner. Animal models including disease or knockout models allow a broad spectrum of experimental manipulations not applicable in humans. The non-invasive fMRI approach provides a promising tool for cross-species comparative investigations. This review focuses on the principles of "resting-state" functional connectivity analysis and its applications to living animals. The translational aspect from in vivo animal models toward clinical applications in humans is emphasized. We introduce the fMRI-based investigation of the non-human brain's hemodynamics, the methodological issues in the data postprocessing, and the functional data interpretation from different abstraction levels. The longer term goal of integrating fMRI connectivity data with structural connectomes obtained with tracing and optical imaging approaches is presented and will allow the interrogation of $\mathrm{fMRI}$ data in terms of directional flow of information and may identify the structural underpinnings of observed functional connectivity patterns.

Keywords: translational MRI, in vivo animal model, neurodegeneration, connectome, mouse, rats, monkey, gene manipulation

\section{INTRODUCTION}

An unexpected observation in the noisy fMRI signal obtained from humans quietly "resting" in the absence of any specific task has ultimately led to the discovery of a phenomenon now well known as "intrinsic" or "resting-state" functional connectivity $(1,2)$. In 1995, Biswal and colleagues demonstrated that the apparent fMRI noise displayed coherent temporal patterns most prominently at low frequencies within anatomically distinct and spatially distributed neuron populations (3). Many efforts aimed at demonstrating that spontaneous fluctuations in the fMRI signal obtained at "rest" maintain meaningful functional activity $(2,4-6)$. Patterns of functional activity are topologically organized (7-9) within defined brain systems even across species (10), rather than representing artifactual byproducts of non-neurophysiological process including motion, cardiac, or respiratory factors. These landmark studies have received further overwhelming support from different approaches including positron emission tomography (11-13), magnetoencephalography (14), optical imaging 
(15), single-unit and local field potential recordings (16), and electroencephalography $(17,18)$ that systematically investigated ongoing spontaneous brain activity in relation to each other. Nowadays, the investigation of the spontaneous fMRI signal has grown into a major and rapidly expanding field for studying functional brain organization (19). In summary, in vivo imaging becomes an increasingly important phenotyping instrument in order to accelerate our understanding of the architecture in both healthy and diseased brains (20).

Besides the eponymous "resting" condition $(3,11)$, organized spontaneous activity in the fMRI signal has also been demonstrated under various states of consciousness including sleep $(21,22)$, anesthesia (23), coma, and minimally conscious state (24), in developing brain $(18,25)$, aging and brain maturation (26), and their potential genetic aspects $(27,28)$. A major compelling aspect of the fMRI signal has been the organized spontaneous brain activity across different species including mice (29-35), rats (29, 36-42), rabbits (43), dogs (44), and pigeons (45), with monkeys (21, 46-53), mice, and rats (54) representing the largest fraction of "resting-state" (rs-)fMRI investigations.

The purpose of this review is to introduce the principles of rs-fMRI with specification to animal measurements and applications to the animal model. We will address methodological issues from experimental design to rs-fMRI data acquisition. The focus will be on the emerging concept of translational imaging from in vivo animal models of brain diseases to clinical applications in humans that may eventually form the groundwork for fundamentally novel therapeutic approaches. The continuous and compelling engagement is highlighted in studying the functional connectivity patterns underlying cellular and molecular events in living animals since there are currently no sufficient in vitro or in silico models that can serve as alternatives to the use of in vivo animal models (55). This review will provide insights into the broad spectrum of data analysis and their interpretation at different abstraction levels, including voxel-wise statistics and the graph theoretical analysis of functional connectome organization.

\section{EXPLORING FUNCTIONAL CONNECTIVITY IN THE LIVING ANIMAL}

In contrast to the exponential growth of "resting-state" publications in humans (56), functional connectivity investigations of non-human species is considerablyless often applied. Comparative "resting-state" fMRI studies in living animals will accelerate the ability to define and test translational animal models of brain pathophysiology (Figure 1). Altering the physiological condition of the animal model has been demonstrated to influence both brain "wiring" (57) and the patterns of functional connectivity (58). Humans and animals share similar features of functional brain network organization and support perceptual and cognitive core properties that are closely related to behavior $(48,59)$. Animal models allow genetic modification and can provide insights into the functional brain organization and the alterations in different disease models. Appropriate measures of functional connectivity may be used as surrogate markers or potentially biomarkers and may form a readout to validate animal models in conjunction with new therapeutic strategies (46).

\section{Neurophysiological Substrate}

The functional networks revealed by rs-fMRI (Figure 2) provide a more general picture of brain function across species. Brain regions that are coactive during specific tasks (as measured by "task-based" fMRI) tend to be integrated within corresponding functional networks (as obtained by rs-fMRI) (9). This groundbreaking observation in more than 30,000 fMRI data sets by Smith and coworkers (9) allow the conclusion that taskinduced activation maps underestimate the size and number of functionally coupled neuron populations (1). Many suggestions have emerged explaining the underlying mechanisms which link

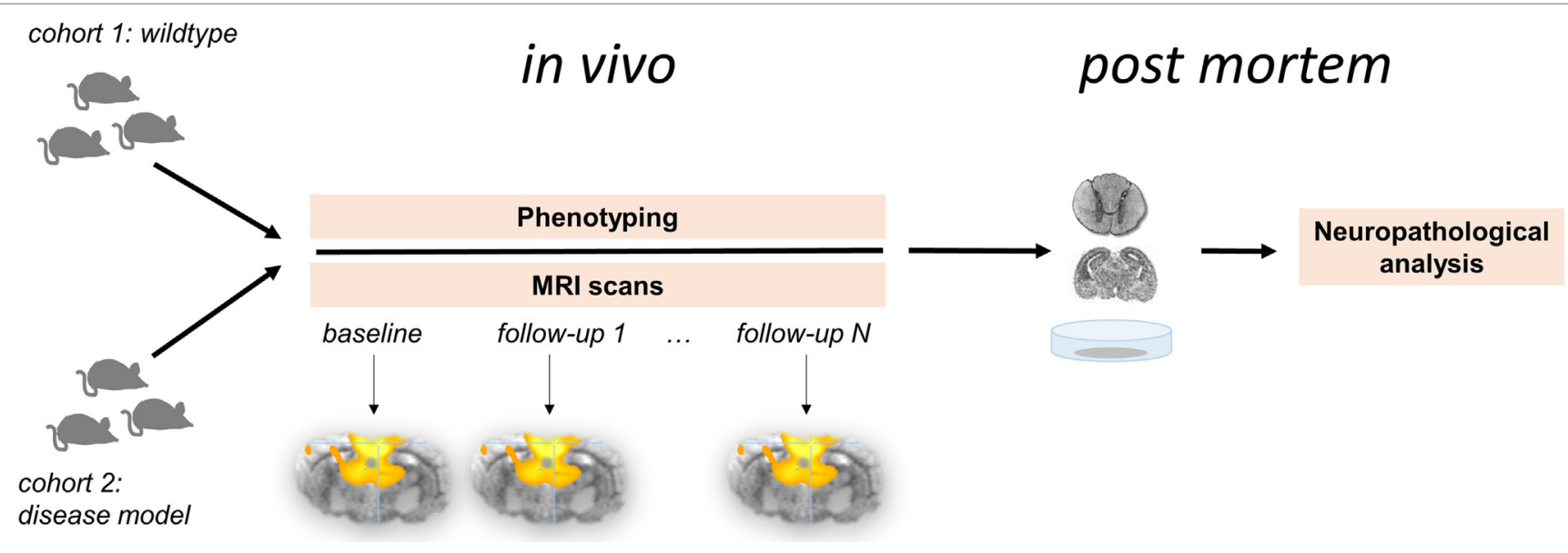

FIGURE 1 | Longitudinal multiparametric study concept for functional connectivity analysis in the animal model. Two cohorts comprising wild-type animals (control group) and disease model undergo in vivo investigations followed by neuropathological analyses post mortem. This study design allows for the systematic analysis for the functional brain organization and its potential changes over time in association with phenotype-depending behavioral and histopathological parameters. 


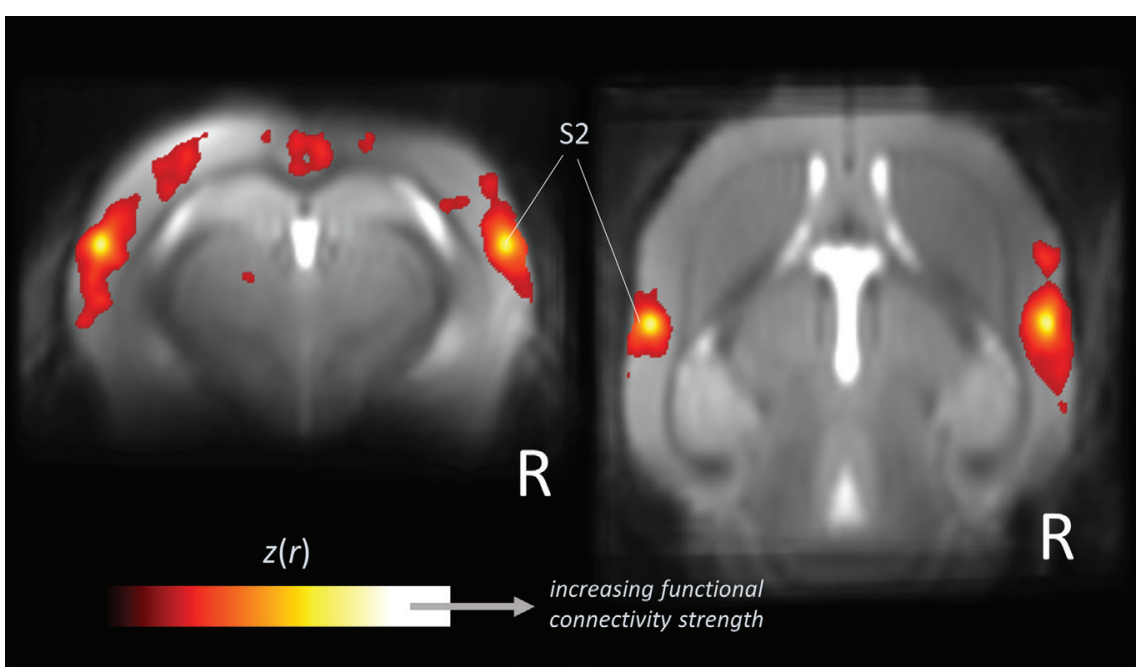

FIGURE 2 | Large-scale correlation patterns of the "resting-state" fMRI signal. Data are shown from five wild-type mice acquired from a high-field (11.7 T) small animal MRI. Orthogonal brain section heat maps showing mean voxels for which the fMRI signal was correlated with bilateral seed regions in secondary somatosensory cortex (S2), which allows the identification of the somatosensory functional motor network. The $z(r)$ values indicate the strength of correlation.

neural activity to hemodynamic responses. There are proposals of rehearsal, learning consolidation, future preparation (60), and variations of neuronal excitability (61), but there is not yet conclusive evidence for any of these concepts. Factors such as anesthesia influence the shape of functional connectivity patterns (62); however, the well-defined networks including the default mode $(32,63)$ remain stable across species and its integrity and topological principles remain preserved as demonstrated for widely dissimilar physiologic states in rats (64).

A further indirect conclusion about the fundamental role of the brains' ongoing activity in (nearby) all species can be drawn from a metabolic perspective since ongoing activity is energetically costly (2) while brain organization across species is economically optimized (65). This statement is in agreement with the fact that the mammalian brain has maintained the hierarchy of brain oscillations, irrespective of the species' brain size (66). Brain oscillations are topologically organized across species which is in line with evolutionary processes (10). Moreover, it appears save to assume that low frequency correlations are a general feature of neural systems (67). Currently, the understanding of ongoing spontaneous activity and its neurophysiological substrate is still under investigation (68).

\section{Animal Models}

Animal research has a pivotal role in neuroscience and has substantially contributed to our understanding of various conditions and diseases. The benefits of animal research have been tremendous and have substantially contributed to ongoing advancement of medicine and neuroscience as well as the health of both human and animals (69). Each experiment in living animals has to be designed within a strict ethical framework. The beneficial effects on humans have been proven, even though scientists are encouraged to further improve better public understanding and to emphasize implications on humans (55).
Comparative conclusions from cross-species functional connectivity investigations argue that the functional interaction of brain networks support the broad variety of different cognitive processes and provide essential features for survival (46). A large body of evidence attributed abnormal functional connectivity patterns to multiple psychiatric, neurological (70), and developmental disorders (71). Since advanced genetic techniques allow manipulation of the genome and precise control of gene expression in rodents, transgenic models of human neuropathology are becoming increasingly important. One challenge is to differentiate between normal aging and the onset of a pathological neurodegenerative processes. For neurodegenerative diseases including Alzheimer's disease, Parkinson's disease, and amyotrophic lateral sclerosis, it is known and broadly accepted that the underlying pathological process in human propagates in a characteristic fashion and can be attributed to different subclinical and clinical disease stages (72). Animal models of functional brain organization at different neurodegenerative disease stages may allow to define possible readouts for possible surrogate markers and enhanced drug trials. Transgenic mouse models of neurodegenerative pathology revealed abnormal functional connectivity patterns in agreement with findings in humans (54). In particular, these findings resulted from studies in cholesterol transporter apolipoprotein $\varepsilon$ (ApoE) mutant mice, a genotype associated with an increased risk to develop neurodegeneration (73). In ApoE4 mice mutants, functional connectivity has been successfully used as a readout to evaluate dietary treatment that improved brain connectivity (74). A role for microglia in promoting the maturation of circuit connectivity during development has been demonstrated in $\mathrm{Cx} 3 \mathrm{cr} 1^{\mathrm{KO}}$ mice compared to wild-type animals by using functional connectivity measures as a readout for neurodevelopmental impairment (71). This study addressed the gap between neurochemical mechanisms of microglia-mediated synaptic pruning und functional connectivity. Many other studies in transgenic models such as autism 
(75) reported abnormal functional connectivity in association with a phenotype. Standardized brain trauma models in animals have not been established yet. Studying functional alterations associated with traumatic injuries (76) under controlled conditions in the animal model may gain detailed insights into altered patterns of functional connectivity and the effects after recovery. We can hypothesize that the functional brain network is regionally damaged and this lesion may trigger functional reorganization as a compensatory response. The impact and its location can be controlled together with the phenotype (transgenic mice models exist that are defined by the responsibility and resistance against traumatic brain injuries) in animal experiments (77), which is not possible in humans. Functional (re-)organization in association with a behavioral correlate could be a valuable readout for the investigation of traumatic injuries.

Thus, as long as we do not have a full brain model proven to provide all complex neural and neurochemical properties necessary for modeling brain dysfunctions and therapeutical concepts for different phenotypes, there will be the need for animal models as a biological system capturing the complex humans' overall brain architecture as closely as possible. Medical advances of the past decades underpin their role in the development of therapeutic concepts that may eventually pave the way for causal treatments of neurodegenerative diseases. Many studies reported altered functional architecture of intrinsic activity in neurological and psychiatric disorders (78); hence, here we review respective studies on translational animals utilizing rs-fMRI. Animal models encompassing disease or knockout models allow for a great range of experimental manipulations which are not applicable to humans. Moreover, postmortem validation of the underlying pathological process-which is very limited in human studies-is easier to achieve in animal studies. Most studies of functional connectivity utilize the non-invasive fMRI approach because it provides a promising tool for cross-species comparative approaches.

\section{PRINCIPLES OF "RESTING-STATE" fMRI DATA ACQUISITION}

In humans, "resting-state" data are easy-to-acquire by typically asking subjects to "rest" quietly with their eyes closed and motionless in the MRI scanner for about $5 \mathrm{~min}$; indeed, "rest" is poorly defined and has been attributed to a control condition in the context of a commonly used block design in "task-based" fMRI studies. The definition of "rest" (or better "task-free" condition) becomes even more complicated and nearby impossible to control for in the context of non-human rs-fMRI. The vast majority of rs-fMRI investigations in animals including small animals require anesthesia which minimizes motion artifacts, physiological stress, and training requirements (46). Motion corruption is a critical issue due to its high susceptibility during fMRI data acquisition (19). Despite the limitations of controlling the "rest" condition and the various types of anesthesia and consciousness states, the functional data are largely comparable even across species.

The "resting-state" fMRI sequence is a $\mathrm{T}_{2}^{*}$-weighted signal that is sensitive for neurally driven changes of the oxy-to-deoxyhemoglobin ratio, i.e., blood oxygenation level dependent (BOLD), which changes the magnetic properties (79). The resulting fMRI data set consists of a series of echo planar images, i.e., volumes that are equidistantly obtained during the scan. The voxel size is identical for each volume and defines the spatial resolution; the time needed to record each volume (repetition time) defines the temporal resolution (79). Table 1 provides representative examples of commonly used scan parameters for rs-fMRI data acquisition in key laboratory animals. The voxel size varies across species depending on the MRI scanner, whereas the typical number of voxels of a brain is relatively constant across species. For instance, a typical voxel size for whole-brain scans of an 11.7-T ultra-highfield MRI used to scan mice is about $150 \mu \mathrm{m} \times 150 \mu \mathrm{m}$ in-plane resolution and 250-500 $\mu \mathrm{m}$ slice thickness; in comparison, a typical spatial resolution of a state-of-the-art $3 \mathrm{~T}$ for humans is about $2 \mathrm{~mm} \times 2 \mathrm{~mm}$ and slice thickness of $1.5-3 \mathrm{~mm}$. Smaller voxel sizes allow a better separation of different tissue types at the expense of adverse signal-to-noise ratio and decreased temporal resolution (a volume takes longer to acquire). Larger voxel sizes covering different tissue types may contain shared hemodynamic activity from different neuronal populations-a phenomenon called partial volume effects. The temporal resolution is typically around $2 \mathrm{~s}$, which is appropriate to measure slow-frequency fluctuations $(<0.1 \mathrm{~Hz})$, i.e., infra-slow waves $(0.01<f<0.10 \mathrm{~Hz})(21)$, as it is intended by "resting-state" fMRI. However, a time repetition is associated with limitations arising from the Nyquist-Shannon "sampling theorem" - a fundamental law of digital signal processing: the frequency band being investigated is limited to $0<f<1$ / $(2 \times \mathrm{TR})$. That means, for TR $=2 \mathrm{~s}$ is the highest frequency $0.25 \mathrm{~Hz}$ and all frequencies $>0.25 \mathrm{~Hz}$ (e.g., cardiac pulse of about $1 \mathrm{~Hz}=60 / \mathrm{min}$ ) are confounding the signal, i.e., aliased, and cannot be filtered. Hence, other frequency bands such as the typical EEG bands ranging from slow-frequency $(0.1-1.0 \mathrm{~Hz})$ and delta

TABLE 1 | State-of-the-art "resting-state" (rs-)fMRI protocols for key laboratory animals compared with humans.

\begin{tabular}{|c|c|c|c|c|}
\hline & Resting-state (rs-)fMRI (mice) (71) & rs-fMRI (rats) (35) & rs-fMRI (monkeys) (83) & rs-fMRI (humans) (84) \\
\hline Field strength $(T)$ & 7.0 & 9.4 & 7.0 & 3.0 \\
\hline Slices, $n$ & 16 & 12 & 30 & 47 \\
\hline Slice thickness (mm) & 0.75 & 1.00 & 1.50 & 3.00 \\
\hline Voxel size $(\mathrm{mm})$ & $0.23 \times 0.23 \times 0.75$ & $0.23 \times 0.23 \times 1.00$ & $1.30 \times 1.30 \times 1.50$ & $3.00 \times 3.00 \times 3.00$ \\
\hline $\mathrm{TR}(\mathrm{ms})$ & 1,000 & 2,000 & 2,000 & 3,000 \\
\hline TE (ms) & 15 & 16 & 16 & 30 \\
\hline FOV (mm) & $23 \times 20 \times 12$ & $30 \times 30 \times 12$ & $96 \times 96 \times 45$ & $216 \times 216 \times 216$ \\
\hline Volumes, $n$ & 360 & 150 & 300 & 124 \\
\hline
\end{tabular}

Depicted are representative scan parameters for whole-brain rs-fMRI data acquisition using echo planar imaging $\left(E P I, T_{2}^{*}\right)$. 
$(1-4 \mathrm{~Hz})(80)$ to gamma $(25-100 \mathrm{~Hz})(81)$ cannot be investigated using "resting-state" fMRI. Efforts have been made and related research continuous to optimize both spatial and temporal resolution by using acceleration techniques to permit more rapid whole-brain-based volume acquisition (82).

\section{ANALYSIS OF SPONTANEOUS NEURAL ACTIVITY FROM THE fMRI SIGNAL}

Although the rs-fMRI data acquisition is relatively easy even in the living animal, the analysis is not. Several major denoising approaches have been suggested to provide an optimal estimate of the neurally driven variance in the "resting-state" fMRI signal. The measured signal is considerably confounded by non-neural signals including motion artifacts, respiration, cardiac pulse, and their variations over time such that only about $4 \%$ of the total variance [for high quality data of the human connectome project (85)] in the fMRI signal accounts for neurally driven signals (86). Hence, the vast majority of the preprocessing pipeline of the fMRI signal copes with denoising of the data, i.e., extracting the neurally driven fMRI signal.

\section{Preprocessing "Resting-State" fMRI Data}

Preprocessing typically includes motion correction, spatial smoothing, temporal demeaning, detrending and band-pass filtering, regression of nuisance covariates, and normalization into a common stereotaxic space (87). These steps are commonly used across species $(32,71,88)$ and are briefly explained. Nearby all fMRI studies correct for motion artifacts that occur even under anesthesia due to respiration, cardiac pulse, and muscle relaxation. Head motion can lead to severe image degradation (89) and can result in false-positive functional connectivity (19). Motion correction can be done by computing an estimate of each volume with respect to a reference volume (e.g., the first volume) for all degrees of freedom $(x, y, z$, pitch, roll, yaw), which allows for a rigid brain transformation (90). Some investigators suggested to withhold motion-contaminated images from analysis and provided elaborated approaches that model motion influences to the fMRI signal $(89,91)$. Spatial filtering is applied to each of the volumes by typically using a Gaussian blur filter (3-D bell shape representing normal distribution) in order to improve the signal-to-noise ratio at the expense of "blurring" the images, i.e., decreasing spatial resolution, according to the "matched filter" design. The filter parameters are given as the full-width at half maximum (FWHM) for each spatial dimension $(x, y, z)$; the filter length of twice the voxel size in dimension given by the scanner protocol is a common choice, e.g., for a (hypothetically) isotropic $(400 \mu \mathrm{m})^{3}$ voxel size of a small animal MRI a good choice would be a Gaussian filter with $800 \mu \mathrm{m}$ FWHM in each dimension (92).

Possible scanner drifts during the rs-fMRI data acquisition should be voxel-wise removed along each time series by linear detrending (93). Linear detrending can be performed by subtracting the linear fit of the voxel time-course. The frequency spectrum of the time series for each voxel is commonly band-pass filtered using cutoff frequencies in the range of about $0.01<f<0.1 \mathrm{~Hz}$ (70), some investigators perform low-pass filtering $(f<0.1 \mathrm{~Hz})$. Temporal filtering is required in order to limit the frequency spectrum to the neurophysiologically interesting infra-slow waves that are termed the spontaneous low frequency fluctuations. Usually, the first volumes (about 10 volumes) are discarded from further analysis due to the transient temporal filter response (87) and to allow the subject to adapted to the experimental condition (94), for instance, relaxation and minor changes in head position due respiratory or cardiac factors may likely occur at the beginning of an experiment even under anesthesia.

Aiming at further denoising, most rs-fMRI investigators remove various nuisance covariates by using non-physiological signals as a regressor in a general linear model (95). These nuisance regressors include motion estimates and tissue-based regressors; in addition, the derivatives and backward differences can be used. Tissue-based regressors can be computed from the averaged signal across voxels form a ventricle mask, from the cerebrospinal fluid signal, from a white matter mask, from a whole-brain mask, and from the signal of the skull or background clutter (91). In summary, preprocessing is mandatory and can substantially improve the data quality in animal MRI scanning, although post hoc rs-fMRI denoising and artifact reduction remains challenging. The discussed preprocessing steps are similar for human and data from living animals.

There are numerous techniques available for denoising the rs-fMRI signal, but there is no gold-standard yet. The performance of these techniques depends on the preprocessing steps utilized and its order (96). A standard preprocessing pipeline can include any of the following steps: motion correction, resampling, removing of non-physiological signals, nuisance regression, temporal filtering, and spatial smoothing. Each of these steps requires a set of parameters. The steps and their order of the preprocessing pipeline should be carefully selected with respect to the MR acquisition parameters, species-specific traits, and the overall aim of the investigation. Table 2 provides a comprehensive summary of commonly used techniques in recent animal rs-fMRI investigations.

\section{Providing Data in a Common Stereotaxic Space}

For data analyses across multiple MRI scans from different animals (of a given species), it is essential to align the acquired echo planar images into a common anatomical space in order to have a clear concept of localization in the brain. That means the spatially matched (i.e., "registered") images should ideally provide the same spatial location in each subject. Good spatial normalization is a challenging procedure given that the brain's complex cortical folding differs dramatically between individuals even of the same species (100). Investigators of human studies typically transform the images into the Montreal Neurological Institute (MNI) stereotaxic standard space (101); common practices are linear and non-linear (non-affine) registration algorithms (102). For animal MRI data, no such commonly accepted stereotaxic standard space has yet emerged, even not for key laboratory animals. However, neuroanatomical information for the adult and developing brain in mice, humans, and other non-human primate from the online public resource Allen Brain Atlas (103) can be used as a template in standardized coordinates. The Allen Mouse brain atlas, for instance, includes a full-color, 
TABLE 2 | Frequently used preprocessing steps in the rs-fMRI data analysis pipeline (including denoising) according to recent animal studies, e.g., Ref. (43, 71, 97-99).

\begin{tabular}{|c|c|c|c|}
\hline & Description & Possible drawbacks & Typical values \\
\hline $\begin{array}{l}\text { Head motion } \\
\text { correction }\end{array}$ & $\begin{array}{l}\text { Reduces the potential influence of head motion (which is also } \\
\text { present in anesthetized animal) }\end{array}$ & Partial volume effects & All six degrees of freedom \\
\hline Resampling & $\begin{array}{l}\text { Provides data in a common grid with user-defined voxel sizes } \\
\text { (which is particularly interesting for merging protocols) }\end{array}$ & Partial volume effects & $\begin{array}{l}\text { Cubic grid, size depends on the species } \\
\text { and overall aim of the rs-fMRl investigation }\end{array}$ \\
\hline $\begin{array}{l}\text { Regression of } \\
\text { nuisance covariates: } \\
\text { global signal }\end{array}$ & $\begin{array}{l}\text { Reduces linear and non-linear dependence of signals that are } \\
\text { assumed to represent no useful physiological information }\end{array}$ & $\begin{array}{l}\text { Removal of superimposed } \\
\text { neural signals }\end{array}$ & $\begin{array}{l}\text { Motion estimates, white matter, CSF, } \\
\text { global signal }\end{array}$ \\
\hline Temporal filtering & $\begin{array}{l}\text { Attenuates non-physiological frequencies and restrict the signal } \\
\text { to the infra-slow wave spectrum }\end{array}$ & $\begin{array}{l}\text { Attenuation of physiological } \\
\text { frequencies around the cut-off } \\
\text { frequencies }\end{array}$ & $0.01 \mathrm{~Hz}<f<0.08 \mathrm{~Hz}$ \\
\hline Spatial smoothing & Increases signal-to-noise ratio by reducing uncorrelated noise & Blurred spatial resolution & $\begin{array}{l}\text { Two times the native spatial resolution } \\
\text { according to the rs-fMRI protocol }\end{array}$ \\
\hline Discarding volumes & $\begin{array}{l}\text { Removes transient temporal filter response and scanner } \\
\text { oscillation at the beginning; allows the subject to adapted to the } \\
\text { condition }\end{array}$ & $\begin{array}{l}\text { Reduction of number of } \\
\text { volumes }\end{array}$ & $10-15$ \\
\hline $\begin{array}{l}\text { Fisher's } r \text {-to-z } \\
\text { transformation }\end{array}$ & Improves normality of correlation coefficients & Non-linear transformation & - \\
\hline
\end{tabular}

high-resolution anatomic reference atlas accompanied by a systematic, hierarchically organized taxonomy of mouse brain structures that can be used as a basis for spatial normalization. A wiring diagram of the whole mouse brain at a mesoscale has been defined using standardized labeling, tracing, and imaging of axonal connections (104). Although the mesoscale structural connectome definition of the mouse has received great support (105), a functional parcellation of the mouse brain has not been presented, so far. For rats, a stereotaxic MRI template set for the rat brain with tissue class distribution has been published (106).

Normalization is generally achieved by co-registering all images from a study to a common echo planar image template (101). Different algorithms can be utilized to warp the individual images on the common template $(107,108)$. These commonly applied algorithms use a multiparametric affine transformation followed by non-linear mean squared difference matching. The normalization approach is principally similar for animal MRI data and humans and the quality of normalization into a common space mainly depends on the used template. The template image used could be one predefined template such as MNI template for humans (109) or a study-specific template can be created by averaging across a number of different subjects (e.g., whole study population, sub-cohort regarding phenotype, age, scanner protocol) that have been transformed in a common space (110). Customized study-specific templates in a common stereotaxic space are highly recommended for registrations purposes (111) because inter-subject normalization within the study cohort, for instance, with respect to global brain atrophy (e.g., in neurodegenerative disease models), is considerably improved. State-ofthe-art animal fMRI analyses techniques (71) used a digitalized version of a mouse brain atlas utilized to create a template for fMRI data analysis. For instance, "resting-state" in dogs (44), a rarely investigated species for which no well-accepted brain atlas in a common space exist, used the functional image of one dog as the template on which the other dog was matched on. Normalization without using a common template can be performed by defining landmarks that allow a transformation according to the coordinates of these landmarks. Müller et al. (108) has suggest a landmark-based normalization procedure prior to a registration to a common template by manually defining eight landmarks in the first volume for each rodent $(57,112)$, a procedure adapted from human studies. The normalization procedure is typically refined by non-linear normalization of the individual echo planar images onto the study-specific template following the basic ideas of Ashburner and Friston (107) of minimizing the squared differences of regional intensities. In summary, the quality of normalization determines the ability to compare results between subjects or groups. At least small errors are inherent to any normalization procedure and differences in individual brain anatomy including the complex cortical convolution cannot be completely overcome by normalization into a common stereotaxic space.

\section{Functional Connectivity-Based Brain Parcellation}

For spatial normalization, (study-specific) templates are required. Templates commonly refer to atlas-based definitions of the respective species (103), but the underlying brain structure does not adequately capture functionally segregated modules, i.e., "nodes" in the graph theoretical context, because it involves the risk of mixing different time courses within a single node (113) The definition of nodes across the whole brain is challenging but mandatory for robust and reliable functional connectivity analyses. Data-driven approaches including independent component analysis (114) have been introduced for brain parcellation and for delineating resting-state functional networks in humans (115) and rodent (32). Graph theory-based approaches provide another data-driven approach for functional brain network identification without the need for a priori information (116). A data-driven whole-brain functional parcellation algorithm that jointly optimizes the group and the individual parcellation has been introduced for the human brain $(113,117)$. The resulting functional brain atlas has been released (113), and it comprises up to approximately 300 functionally homogeneous subunits. The application of this data-driven procedure to rs-fMRI data 
of animals could be promising for studying functional brain organization more accurately, which is mainly important when behavioral differences between groups or across time are being analyzed.

\section{Functional Connectivity Measures}

After the rs-fMRI data have undergone steps of preprocessing, a broad spectrum of functional connectivity analysis methods including measures of coherences, frequency spectral analysis, dynamics, and causal influences among time series is available (118). The simplest measure of signal similarity is the Pearson correlation coefficient which is widely used to measure the strength of pairwise region-to-region connectivity of the slow BOLD fluctuations and which allows for the definition of functional connectivity networks (Figure 3). The specification of regions of interests (also termed "seeds") depends on the study design and is by definition a hypothesis-driven approach (119), in contrast to data-driven independent component analysis (mentioned as a tool for denoising), a mathematically sophisticated signal decomposition technique that allows to separate various "independent" sources (114). Both techniques have been successfully applied to investigate functional connectivity organization in human and living animals including rodents $(32,71)$.

The set of pairwise region-to-region connectivity measures (e.g., Pearson's correlations) obtained from a fine-grain voxelwise parcellation of the brain can be used for graph theoretic analysis at a higher abstraction level (120). A brain's functional organization has features of complex networks at the whole-brain

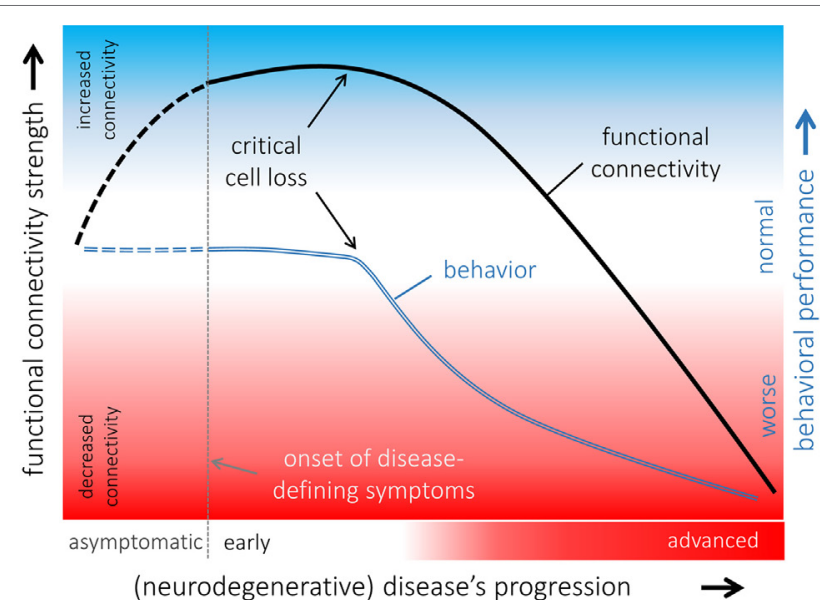

FIGURE 3 | Hypothetical model of functional connectivity alterations in association with behavioral performance in the course of neurodegeneration. The pattern of functional connectivity changes (black line) and its association with behavior (blue line) indicated that functional connectivity increases in a potentially compensatory response to ongoing cell degeneration in order to maintain "normal" behavioral performance as long as possible. When a critical cell loss is reached, i.e., the functional reserves are exhausted, behavioral performance declines, and functional connectivity decreases upon a disconnection syndrome with poor behavioral performances presented in an advanced disease state. It remains open whether functional connectivity is already altered in an asymptomatic phase of an underlying neurodegenerative pathological process (dashed lines). scale and the cellular level (121). Connectome-related differences in brains across species follow an allometric scaling relation across the entire spectrum of simpler to higher order species (10). Features such as highly connected neuron populations ("hubs") (122), modularity (116), rich-club organization (123), and efficient small-world topology (70) can be systematically quantified by means of graph theory (124) across species.

Recent advances in mathematical tools to infer connectivity and to estimate the connectivity strength have been made, which are particularly useful in small samples as it is the case for most animal rs-fMRI studies. Graphical models that allow to reach reliable estimation of the inverse covariance even when the sample size is close to or even less than the number of brain regions investigated have been demonstrated in positron emission tomography-based connectivity analysis to be promising candidates for rs-fMRI investigations (125). Moreover, graphical models allow for graph-based analysis and have been proven to be used in a discriminative way in an unsupervised classification framework (126). These approaches in pattern classification and unsupervised learning algorithms allow to separate groups, e.g., with respect to the disease model, on the basis of features extracted from imaging data as proven in human studies $(127,128)$.

\section{Longitudinal Data}

The conceptual design of multiparametric studies (as illustrated in Figure 1) highlights the increasing importance of longitudinal measurements (129). Follow-up data enable to investigate the intra-subject rate of functional connectivity changes over time, which is especially useful when studying developmental processes or tracing the course of disease propagation (98). Information on intra-subject changes over time additionally allow to longitudinally compare groups with each other in order to investigate whether multiple groups, e.g., different phenotypes, change over time with respect to functional brain connectivity alterations across a time period of interest. Longitudinal studies in animals, in particular in rodents, are of special interest since the study can be designed across the entire lifespan in contrast to humans where longitudinal studies have to be designed for many years or even decades to capture a sizeable part of the human lifespan.

\section{INTERPRETATION OF FUNCTIONAL CONNECTIVITY DATA}

At the very basic level, strong patterns of low-frequency BOLD coherence among functionally related brain areas creates strong suspicion that two (anatomically) distinct brain regions are neurally communicating in an organized fashion. The brain's many regions - in humans and living animals - appear to functionally interact with each other in the "resting" condition (130) and even when a subject (24) or an animal is under anesthesia (53). The very nature of the underlying neurophysiological mechanism still remains not fully explained; however, many conclusions can be drawn about the functional brain organization. In what follows sheds light on commonly observed rs-fMRI patterns in healthy and diseased brains and their possible interpretation. 


\section{"To Rise and to Fall": On the Meaning of Altered Functional Connectivity}

It is safe to assume that each deviation from "normal" connectivity represents an abnormal possibly pathological condition of the brain (131), although the very nature of the underlying ongoing BOLD fluctuations under diverse conditions ranging from "rest" to deep anesthesia across species is not fully understood. Functional connectivity can alter in both directions defining decreased (hypo-) and increased (hyperconnectivity) conditions, as observed from "seed-based" correlation analysis.

It is virtually straightforward to explain decreased functional connectivity that may eventually lead to a full disconnection syndrome in the context of cell degeneration or impaired functioning of segregated brain modules. Disrupted functional integration with decreased connectivity is associated with cognitive deficits (132) and poor behavioral performance as demonstrated in transgenic mice (71).

By contrast, increased functional connectivity, i.e., stronger BOLD synchronization, is more challenging to interpret; increased functional connectivity has been demonstrated in various neurodegenerative conditions in human studies (133-137) and in rats $(138,139)$. Increased functional connectivity is often interpreted as an adaptive response to an underlying pathological process that could be explained by recruiting additional "resources" by functional reorganization in order to compensate for neural malfunctions and to maintain cognitive and physical performance (136). This model is supported by rs-fMRI investigations in rats following neuropathic injury (138) where functional reorganization including patterns of increased functional connectivity has been demonstrated. At a clinical level, in patients with Parkinson's disease, who exhibit a neuropsychologically confirmed "normal" cognitive performance, the observed patterns of increased functional connectivity across cortical functional networks in comparison with age-matched healthy controls are likely attributed to functional "compensatory" reorganization (135) in general agreement with finding in rats. There is growing evidence that increased functional connectivity can be the first state of abnormal brain functioning in neurological conditions including epilepsy as demonstrated for rats (139) and in the course of neurodegenerative diseases $(131,135)$. Given that functional connectivity is increased in an early state of the disease and a disconnection syndrome is present in an advanced state of the disease due to ongoing cell damage, a hypothetical model of functional connectivity alterations in association with behavioral performance can be proposed (Figure 3): functional connectivity increases upon the neural "reserves" are exhausted while maintaining "normal" behavior. Due to ongoing cell loss (e.g., neurodegenerative disease) or focal damage of respective functional modules (e.g., traumatic brain injury), core nodes of the respective functional connectivity networks decreases functional connectivity with other nodes of the networks and become eventually functionally disconnected in case of ongoing cell loss without remission (137). The likely transient state from patterns of increased to decreased functional connectivity may be accompanied by behavioral and cognitive decline. There appears to be increased functional coupling in the asymptomatic phase of neurodegenerative diseases consistent with our model as supported by a recent study on subjects at genetic risk (140). This further calls transgenic animal models to validate the suggested model of functional alterations in the course of a disease and animal studies with prospective to define abnormal patterns of functional connectivity prior to disease onset are required.

Another explanation for increased functional connectivity could be the loss of the inhibitory influence that may lead to pathological firing associated with abnormally increased functional connectivity (133). This would mean that brain regions excessively firing in a coherent fashion are no longer able to both share "useful" information with each or to interact with other functional modules $(87,137)$. Animal models are needed to challenge this hypothesis and to investigate the pathophysiology of increased functional connectivity in more detail.

\section{Connectomics-Functional Connectivity from a Network Perspective}

The brain is an efficient representation of a complex system $(65,141)$ and has remarkable properties across species. It consists of spatially distributed and functionally specialized regions that continuously share information with each other (70). Graph theoretical approaches for the analysis of functional networks provide a powerful way of quantifying properties of the brain's functional system (121). A functional network is defined in graph theory as a set of nodes, i.e., functionally segregated brain regions, and edges, i.e., a functional connectivity measure, between two nodes (123). The definition of nodes is a critical factor as discussed in the context of (functional) brain parcellation. Given that a set of a sufficient number of nodes has been defined, graph topology can be quantitatively described by a broad spectrum of network measures. An association matrix of functional connectivity measures form the basis for a graph analysis (142) and contains pairwise measures of functional connectivity, typically Pearson's correlation coefficient of slow BOLD fluctuations in both nodes. Many measures of useful properties that characterize the functional network organization can be computed including basic concepts, measures of segregation, integration, motifs, and resilience, and other concepts such as "network small-worldness" (124). The graph theoretical measure that is going to be applied should be guided according to a clear hypothesis and is fully appropriate for functional connectivity investigations in the animal model. For instance, a graph theoretical approach has been recently applied for the investigation of functional connectivity in rats prior and after stressful event exposure (143) and in rats following neuropathic injury (138). The basic concept of graph-based connectomic analysis between the animals' and the humans' brain are nearby identical, and it has been demonstrated that fundamental properties of brain topology in rats are conserved in the same manner as in the human brain (38). In summary, modeling the functional brain connectivity as a graph, with nodes being segregated functional modules and edges being functional "region-to-region" connectivity strengths, opens a new avenue for investigating functional brain organization in multiple neurological and psychiatric conditions in a translational framework. 


\section{Limitations and Pitfalls}

The presence of noise and artifacts limits the study of functional brain organization and inadequate removal of artifact can fundamentally change the conclusions of each and every rs-fMRI study. However, a perfect separation between neurally driven BOLD activity and noise is practically impossible (144), despite the many advanced and continuing efforts being made for denoising the fMRI signal (145). Thus, it is crucial to interpret the outcomes with caution. The nature of BOLD fluctuations and the temporally correlated characteristics are an indirect measure for functional connectivity and is technically constrained by the poor signal-to-noise ratio and limited spatial resolution (146) although many advances in scanner technology, image acquisition protocols, and experimental design have emerged (79). The spatial and temporal limitations of the "noisy" BOLD signal could not be fully overcome by the standardized preprocessing pipeline for fMRI data (147) and conclusions drawn should always incorporate the given limitations of the methodology. However, improvements of analysis techniques have considerably helped to improve the results toward a more reliable interpretation that always have to be seen in a context with the conclusions drawn from the functional MRI data across species.

Various states of consciousness and possible drug administration cannot be (fully) disentangled from "normal" variability of patterns in functional brain connectivity. Many factors dynamically confound brain functioning, and the challenge remains to define robust measures that allow for the definition of an abnormal or pathological state. Caution must be taken when interpreting functional connectivity data since network measures were bound to be unstable across thresholds, i.e., thresholds that defined whether two voxels are functionally connected with each other (148). This methodological limitation has been overcome by an elaborated connectome-based functional connectivity analysis based on a data-driven graph-based parcellation analysis (113) such that functional connectivity profiles act as a "fingerprint" and are both robust and reliable across subjects (149). Comparing groups that may exhibit systematic differences, e.g., motion, can confound the results, e.g., in disease models of movement disorders.

The contribution of inhibitory and excitatory neuronal coupling to functional connectivity measures cannot be disentangled (8). The by-default limited spatial resolution of "resting-state" data and the limited signal-to-noise ratio of the BOLD signal make spatial smoothing a necessary preprocessing analysis step, in order to increase the signal-to-noise ratio, at the expense of partially mixing the signal between gray matter and the neighboring white matter. Hence, the clusters cannot be fully disentangled between gray and white matter. The animals' head motion-induced artifacts-even present under anesthesia-might contribute to the rs-fMRI signal and are believed to produce spurious correlation patterns (19), which should be considered in any interpretation of the results.

\section{Toward the Integration of Structural Connectomes and fMRI Functional Connectivity}

In the last few years, large-scale mapping of physical connectivity in the rodent brain has become feasible, thanks to the convergence of viral and non-viral tracing approaches with high-throughput technologies for image acquisition and image reconstruction. The Allen Mouse Brain Connectivity Atlas (104) initiative has used adeno-associated virus to express green fluorescent protein systematically across a large number of cortical and subcortical structures and then, using a dedicated imaging technique based on serial sectioning and two-photon imaging, has produced imaging datasets spanning the whole mouse brain for each of the injection. Once reconstructed, the resulting database has provided mesoscale connectivity down to cellular level. An independent effort, based on non-viral tracing systems (150), has provided a comparable connectome map with mesoscale resolution in which cortical subnetworks could be identified. Additional connectome datasets with cellular resolution have been obtained for specific subnetworks such as basal ganglia (151). These structural information provide a conceptual framework for the interpretation of functional connectivity data by allowing the selection of subnetworks, to be explored in fMRI data, based on the known directionality of connections between areas. However, each node of the mesoscale maps is populated by multiple local microcircuits endowed with both long- and shortrange connectivity. While this subpopulation of neurons may not be directly detectable by fMRI data, they may have a significant footprint in terms of brain-wide activity. These subnetworks are now also amenable for investigation and manipulation: the use of rabies vectors (152) allows retrograde monosynaptically connected neuronal networks to be imaged at very high resolution [e.g., Ref. (153)] and directionality of connectivity can be used to complement fMRI information (e.g., by reconstructing all synaptically connected input to a given structure). In other terms, once the spreading of functional events within networks is observed, the structural datasets either at mesoscale or at single-cell resolution allow their direct mechanistic interpretations in terms of the simplest neuronal ensembles involved in the generation of the observed functional patterns.

In particular, the directionality of connectivity is, theoretically, easy to determine in structural connectomes since the origin of the axons and their destination can be distinguished; however, the existence of dense networks of reciprocal connectivity [in cortico-cortical or cortico-subcortical loops (104)] may require additional experimental strategies (e.g., in vivo silencing via chemio- or optogenetics) to determine the causal chain of connectivity.

Mesoscale connectomes obtained with current optical imaging technologies may offer a significant resolution advantage compared to MRI techniques (single axons can be individually resolved) although the size of the source volume (e.g., the volume of the injection site) encompasses several whole cortical columns; however, the structural connectomes do not offer a dynamic image of the connectivity but only a static picture of the averaged connectivity diagram. Furthermore, structural data do not hint at the relative functional importance of connectivity: a small number of axons from modulatory subcortical structures may have a much larger impact on the dynamic organization of functional networks than large number of intracortical connectivity.

In order to achieve the most effective combination of highresolution connectomes and fMRI connectivity maps, the 
integration of datasets obtained with largely distinct technological platforms will become necessary, including approaches for coregistering datasets with very different resolution. Ideally, the use of light-sheet microscopes may allow the coregistration of the same brain samples first in fMRI in vivo and thereafter at singlecell resolution ex vivo, allowing functional-structural connectivity to be correlated at single individual level.

\section{CONCLUDING REMARKS}

"Resting-state" functional connectivity analysis is a rapidly expanding approach to study the functional brain organization and has emerged as a major area of neuroimaging in both humans and animals. The emerging view that intrinsic activity might provide a more complete picture of brain function than task-induced activity has opened new pathways and allows for functional connectivity investigations even in anesthetized animals. Extending the use of rs-fMRI investigations in various types of clinical conditions using appropriate animal models is a promising avenue of ongoing research that may help to form a groundwork for understanding the fundamental properties of the functional organization in such models in a unique way $(105,150)$. Continuing research of functional organization in key laboratory animals (e.g., macaque and rodents) may allow for the definition of imaging surrogate

\section{REFERENCES}

1. Biswal BB. Resting state fMRI: a personal history. Neuroimage (2012) 62:938-44. doi:10.1016/j.neuroimage.2012.01.090

2. Raichle ME. Two views of brain function. Trends Cogn Sci (2010) 14:180-90. doi:10.1016/j.tics.2010.01.008

3. Biswal B, Yetkin FZ, Haughton VM, Hyde JS. Functional connectivity in the motor cortex of resting human brain using echo-planar MRI. Magn Reson Med (1995) 34:537-41. doi:10.1002/mrm.1910340409

4. Van Dijk KRA, Hedden T, Venkataraman A, Evans KC, Lazar SW, Buckner RL. Intrinsic functional connectivity as a tool for human connectomics: theory, properties, and optimization. J Neurophysiol (2010) 103:297-321. doi:10.1152/jn.00783.2009

5. Mantini D, Perrucci MG, Del Gratta C, Romani GL, Corbetta M. Electrophysiological signatures of resting state networks in the human brain. Proc Natl Acad Sci U S A (2007) 104:13170-5. doi:10.1073/pnas. 0700668104

6. Oeltermann A, Augath MA, Logothetis NK. Simultaneous recording of neuronal signals and functional NMR imaging. Magn Reson Imaging (2007) 25:760-74. doi:10.1016/j.mri.2007.03.015

7. Laird AR, Fox PM, Eickhoff SB, Turner JA, Ray KL, McKay DR, et al. Behavioral interpretations of intrinsic connectivity networks. J Cogn Neurosci (2011) 23:4022-37. doi:10.1162/jocn_a_00077

8. Park H-J, Friston K. Structural and functional brain networks: from connections to cognition. Science (2013) 342:1238411. doi:10.1126/science.1238411

9. Smith SM, Fox PT, Miller KL, Glahn DC, Fox PM, Mackay CE, et al. Correspondence of the brain's functional architecture during activation and rest. Proc Natl Acad Sci U S A (2009) 106:13040-5. doi:10.1073/pnas. 0905267106

10. van den Heuvel MP, Bullmore ET, Sporns O. Comparative connectomics. Trends Cogn Sci (2016) 20:345-61. doi:10.1016/j.tics.2016.03.001

11. Raichle ME, MacLeod AM, Snyder AZ, Powers WJ, Gusnard DA, Shulman GL. A default mode of brain function. Proc Natl Acad Sci U S A (2001) 98:676-82. doi:10.1073/pnas.98.2.676

12. Shulman GL, Fiez JA, Corbetta M, Buckner RL, Miezin FM, Raichle ME, et al. Common blood flow changes across visual tasks: II. Decreases in cerebral cortex. J Cogn Neurosci (1997) 9:648-63. doi:10.1162/jocn.1997.9.5.624 marker in the future that may support the development of new causal therapeutic concepts. Computational methods excluding animal experimentation underlie many limitations in addressing the understanding of brain function. Today, translational frameworks including various models are more necessary than ever for the study of the brain's function and dysfunction across the lifespan or the full course of the disease.

\section{AUTHOR CONTRIBUTIONS}

MG and JK drafted the manuscript. H-PM, FR, VR, and AL revised the manuscript for intellectual content. All the authors performed literature research, agreed to be accountable for the content of the work, and finally approved the manuscript.

\section{ACKNOWLEDGMENTS}

Small animal imaging is part of the core facilities at Ulm University, Ulm, Germany, and integrated in the center for translational imaging "From Molecule to Man" (MoMan).

\section{FUNDING}

This study had no external funding.

13. Wehrl HF, Hossain M, Lankes K, Liu C-C, Bezrukov I, Martirosian P, et al Simultaneous PET-MRI reveals brain function in activated and resting state on metabolic, hemodynamic and multiple temporal scales. Nat Med (2013) 19:1184-9. doi:10.1038/nm.3290

14. Allen EA, Erhardt EB, Damaraju E, Gruner W, Segall JM, Silva RF, et al. A baseline for the multivariate comparison of resting-state networks. Front Syst Neurosci (2011) 5:2. doi:10.3389/fnsys.2011.00002

15. Guevara E, Sadekova N, Girouard H, Lesage F. Optical imaging of restingstate functional connectivity in a novel arterial stiffness model. Biomed Opt Express (2013) 4:2332-46. doi:10.1364/BOE.4.002332

16. Schölvinck ML, Maier A, Ye FQ, Duyn JH, Leopold DA. Neural basis of global resting-state fMRI activity. Proc Natl Acad Sci U S A (2010) 107:10238-43. doi:10.1073/pnas.0913110107

17. Laufs $\mathrm{H}$. Multimodal analysis of resting state cortical activity: what does EEG add to our knowledge of resting state BOLD networks? Neuroimage (2010) 52:1171-2. doi:10.1016/j.neuroimage.2010.05.034

18. Pizoli CE, Shah MN, Snyder AZ, Shimony JS, Limbrick DD, Raichle ME, et al. Resting-state activity in development and maintenance of normal brain function. Proc Natl Acad Sci U S A (2011) 108:11638-43. doi:10.1073/ pnas. 1109144108

19. Power JD, Barnes KA, Snyder AZ, Schlaggar BL, Petersen SE. Spurious but systematic correlations in functional connectivity MRI networks arise from subject motion. Neuroimage (2012) 59:2142-54. doi:10.1016/j. neuroimage.2011.10.018

20. Kassubek J. The application of neuroimaging to healthy and diseased brains: present and future. Front Neurol (2017) 8:61. doi:10.3389/fneur. 2017.00061

21. Mitra A, Snyder AZ, Tagliazucchi E, Laufs H, Raichle ME. Propagated infraslow intrinsic brain activity reorganizes across wake and slow wave sleep. Elife (2015) 4:R774-88. doi:10.7554/eLife.10781

22. Tagliazucchi E, Laufs H. Decoding wakefulness levels from typical fMRI resting-state data reveals reliable drifts between wakefulness and sleep. Neuron (2014) 82:695-708. doi:10.1016/j.neuron.2014.03.020

23. Kiviniemi V, Jauhiainen J, Tervonen O, Pääkkö E, Oikarinen J, Vainionpää V, et al. Slow vasomotor fluctuation in fMRI of anesthetized child brain. Magn Reson Med (2000) 44:373-8. doi:10.1002/1522-2594 (200009)44:3<373::AID-MRM5>3.0.CO;2-P 
24. Heine L, Soddu A, Gómez F, Vanhaudenhuyse A, Tshibanda L, Thonnard M, et al. Resting state networks and consciousness. Front Psychol (2012) 3:295. doi:10.3389/fpsyg.2012.00295

25. Smyser CD, Snyder AZ, Neil JJ. Functional connectivity MRI in infants: exploration of the functional organization of the developing brain. Neuroimage (2011) 56:1437-52. doi:10.1016/j.neuroimage.2011.02.073

26. Dosenbach NUF, Nardos B, Cohen AL, Fair DA, Power JD, Church JA, et al. Prediction of individual brain maturity using fMRI. Science (2010) 329:1358-61. doi:10.1126/science.1194144

27. Fornito A, Zalesky A, Bassett DS, Meunier D, Ellison-Wright I, Yucel M, et al. Genetic influences on cost-efficient organization of human cortical functional networks. J Neurosci (2011) 31:3261-70. doi:10.1523/JNEUROSCI. 4858-10.2011

28. Markett S, de Reus MA, Reuter M, Montag C, Weber B, Schoene-Bake J-C, et al. Serotonin and the brain's rich club-association between molecular genetic variation on the TPH2 gene and the structural connectome. Cereb Cortex (2016) 27(3):2166-74. doi:10.1093/cercor/bhw059

29. Jonckers E, Van Audekerke J, De Visscher G, Van der Linden A, Verhoye M. Functional connectivity fMRI of the rodent brain: comparison of functional connectivity networks in rat and mouse. PLoS One (2011) 6:e18876. doi:10.1371/journal.pone.0018876

30. Liska A, Galbusera A, Schwarz AJ, Gozzi A. Functional connectivity hubs of the mouse brain. Neuroimage (2015) 115:281-91. doi:10.1016/j. neuroimage.2015.04.033

31. Maier FC, Wehrl HF, Schmid AM, Mannheim JG, Wiehr S, Lerdkrai C, et al. Longitudinal PET-MRI reveals $\beta$-amyloid deposition and $\mathrm{rCBF}$ dynamics and connects vascular amyloidosis to quantitative loss of perfusion. Nat Med (2014) 20:1485-92. doi:10.1038/nm.3734

32. Sforazzini F, Schwarz AJ, Galbusera A, Bifone A, Gozzi A. Distributed BOLD and $\mathrm{CBV}$-weighted resting-state networks in the mouse brain. Neuroimage (2014) 87:403-15. doi:10.1016/j.neuroimage.2013.09.050

33. Stafford JM, Jarrett BR, Miranda-Dominguez O, Mills BD, Cain N, Mihalas S, et al. Large-scale topology and the default mode network in the mouse connectome. Proc Natl Acad Sci U S A (2014) 111:201404346. doi:10.1073/ pnas. 1404346111

34. Tobin JE, Xie M, Le TQ, Song S-K, Armstrong RC. Reduced axonopathy and enhanced remyelination after chronic demyelination in fibroblast growth factor 2 (Fgf2)-null mice: differential detection with diffusion tensor imaging. J Neuropathol Exp Neurol (2011) 70:157-65. doi:10.1097/ NEN.0b013e31820937e4

35. White BR, Bauer AQ, Snyder AZ, Schlaggar BL, Lee JM, Culver JP. Imaging of functional connectivity in the mouse brain. PLoS One (2011) 6:e16322. doi:10.1371/journal.pone.0016322

36. Hutchison RM, Mirsattari SM, Jones CK, Gati JS, Leung LS. Functional networks in the anesthetized rat brain revealed by independent component analysis of resting-state fMRI. J Neurophysiol (2010) 103:3398-406. doi:10.1152/jn.00141.2010

37. Hyde JS, Li R. Functional connectivity in rat brain at $200 \mu \mathrm{m}$ resolution. Brain Connect (2014) 4:470-80. doi:10.1089/brain.2014.0281

38. Liang Z, King J, Zhang N. Uncovering intrinsic connectional architecture of functional networks in awake rat brain. J Neurosci (2011) 31:3776-83. doi:10.1523/JNEUROSCI.4557-10.2011

39. Lu H, Zou Q, Gu H, Raichle ME, Stein EA, Yang Y. Rat brains also have a default mode network. Proc Natl Acad Sci U S A (2012) 109:3979-84. doi:10.1073/pnas.1200506109

40. Majeed W, Magnuson M, Keilholz SD. Spatiotemporal dynamics of low frequency fluctuations in BOLD fMRI of the rat. J Magn Reson Imaging (2009) 30:384-93. doi:10.1002/jmri.21848

41. Pawela CP, Biswal BB, Cho YR, Kao DS, Li R, Jones SR, et al. Resting-state functional connectivity of the rat brain. Magn Reson Med (2008) 59:1021-9. doi: $10.1002 / \mathrm{mrm} .21524$

42. Sierakowiak A, Monnot C, Aski SN, Uppman M, Li T-Q, Damberg P, et al. Default mode network, motor network, dorsal and ventral basal ganglia networks in the rat brain: comparison to human networks using resting state-fMRI. PLoS One (2015) 10:e0120345. doi:10.1371/journal. pone. 0120345

43. Schroeder MP, Weiss C, Procissi D, Disterhoft JF, Wang L. Intrinsic connectivity of neural networks in the awake rabbit. Neuroimage (2016) 129:260-7. doi:10.1016/j.neuroimage.2016.01.010
44. Berns GS, Brooks AM, Spivak M. Functional MRI in awake unrestrained dogs. PLoS One (2012) 7:e38027. doi:10.1371/journal.pone.0038027

45. De Groof G, Jonckers E, Güntürkün O, Denolf P, Van Auderkerke J, Van der Linden A. Functional MRI and functional connectivity of the visual system of awake pigeons. Behav Brain Res (2013) 239:43-50. doi:10.1016/j. bbr.2012.10.044

46. Hutchison RM, Everling S. Monkey in the middle: why non-human primates are needed to bridge the gap in resting-state investigations. Front Neuroanat (2012) 6:29. doi:10.3389/fnana.2012.00029

47. Hutchison RM, Leung LS, Mirsattari SM, Gati JS, Menon RS, Everling S. Resting-state networks in the macaque at 7T. Neuroimage (2011) 56:1546-55. doi:10.1016/j.neuroimage.2011.02.063

48. Hutchison RM, Womelsdorf T, Gati JS, Everling S, Menon RS. Resting-state networks show dynamic functional connectivity in awake humans and anesthetized macaques. Hum Brain Mapp (2013) 34:2154-77. doi:10.1002/ hbm. 22058

49. Liu JV, Hirano Y, Nascimento GC, Stefanovic B, Leopold DA, Silva AC. fMRI in the awake marmoset: somatosensory-evoked responses, functional connectivity, and comparison with propofol anesthesia. Neuroimage (2013) 78:186-95. doi:10.1016/j.neuroimage.2013.03.038

50. Mantini D, Gerits A, Nelissen K, Durand J-B, Joly O, Simone L, et al. Default mode of brain function in monkeys. J Neurosci (2011) 31:12954-62. doi:10.1523/JNEUROSCI.2318-11.2011

51. Moeller S, Nallasamy N, Tsao DY, Freiwald WA. Functional connectivity of the macaque brain across stimulus and arousal states. J Neurosci (2009) 29:5897-909. doi:10.1523/JNEUROSCI.0220-09.2009

52. Rilling JK, Barks SK, Parr LA, Preuss TM, Faber TL, Pagnoni G, et al. A comparison of resting-state brain activity in humans and chimpanzees. Proc Natl Acad Sci U S A (2007) 104:17146-51. doi:10.1073/pnas.0705132104

53. Vincent JL, Patel GH, Fox MD, Snyder AZ, Baker JT, Van Essen DC, et al. Intrinsic functional architecture in the anaesthetized monkey brain. Nature (2007) 447:83-6. doi:10.1038/nature05758

54. Gozzi A, Schwarz AJ. Large-scale functional connectivity networks in the rodent brain. Neuroimage (2015) 127:496-509. doi:10.1016/j.neuroimage. 2015.12.017

55. Bennett AJ, Ringach DL. Animal research in neuroscience: a duty to engage. Neuron (2016) 92:653-7. doi:10.1016/j.neuron.2016.10.034

56. Snyder AZ, Raichle ME. A brief history of the resting state: the Washington University perspective. Neuroimage (2012) 62:902-10. doi:10.1016/j. neuroimage.2012.01.044

57. Müller H-P, Kassubek J, Vernikouskaya I, Ludolph AC, Stiller D, Rasche V. Diffusion tensor magnetic resonance imaging of the brain in APP transgenic mice: a cohort study. PLoS One (2013) 8:e67630. doi:10.1371/journal. pone. 0067630

58. Pawela CP, Biswal BB, Hudetz AG, Li R, Jones SR, Cho YR, et al. Interhemispheric neuroplasticity following limb deafferentation detected by resting-state functional connectivity magnetic resonance imaging (fcMRI) and functional magnetic resonance imaging (fMRI). Neuroimage (2010) 49:2467-78. doi:10.1016/j.neuroimage.2009.09.054

59. Pan W-J, Billings JCW, Grooms JK, Shakil S, Keilholz SD. Considerations for resting state functional MRI and functional connectivity studies in rodents. Front Neurosci (2015) 9:269. doi:10.3389/fnins.2015.00269

60. Buckner RL, Vincent JL. Unrest at rest: default activity and spontaneous network correlations. Neuroimage (2007) 37:1091-6. doi:10.1016/j. neuroimage.2007.01.010

61. Raichle ME. The restless brain. Brain Connect (2011) 1:3-12. doi:10.1089/ brain.2011.0019

62. Nallasamy N, Tsao DY. Functional connectivity in the brain: effects of anesthesia. Neuroscientist (2011) 17:94-106. doi:10.1177/1073858410374126

63. Buckner RL, Andrews-Hanna JR, Schacter DL. The brain's default network: anatomy, function, and relevance to disease. Ann N Y Acad Sci (2008) 1124:1-38. doi:10.1196/annals.1440.011

64. Liang Z, King J, Zhang N. Intrinsic organization of the anesthetized brain. J Neurosci (2012) 32:10183-91. doi:10.1523/JNEUROSCI.1020-12.2012

65. Bullmore E, Sporns O. The economy of brain network organization. Nat Rev Neurosci (2012) 13:336-49. doi:10.1038/nrn3214

66. Buzsáki G, Logothetis N, Singer W. Scaling brain size, keeping timing: evolutionary preservation of brain rhythms. Neuron (2013) 80:751-64. doi:10.1016/j.neuron.2013.10.002 
67. Chen LM, Yang P-F, Wang F, Mishra A, Shi Z, Wu R, et al. Biophysical and neural basis of resting state functional connectivity: evidence from non-human primates. Magn Reson Imaging (2017) 39:71-81. doi:10.1016/j. mri.2017.01.020

68. Raichle ME. The restless brain: how intrinsic activity organizes brain function. Philos Trans R Soc Lond B Biol Sci (2015) 370:20140172. doi:10.1098/ rstb.2014.0172

69. Festing S, Wilkinson R. The ethics of animal research. Talking point on the use of animals in scientific research. EMBO Rep (2007) 8:526-30. doi:10.1038/sj. embor.7400993

70. van den Heuvel MP, Hulshoff Pol HE. Exploring the brain network: a review on resting-state fMRI functional connectivity. Eur Neuropsychopharmacol (2010) 20:519-34. doi:10.1016/j.euroneuro.2010.03.008

71. Zhan Y, Paolicelli RC, Sforazzini F, Weinhard L, Bolasco G, Pagani F, et al. Deficient neuron-microglia signaling results in impaired functional brain connectivity and social behavior. Nat Neurosci (2014) 17:400-6. doi:10.1038/ nn.3641

72. Jucker M, Walker LC. Self-propagation of pathogenic protein aggregates in neurodegenerative diseases. Nature (2013) 501:45-51. doi:10.1038/ nature 12481

73. Zerbi V, Wiesmann M, Emmerzaal TL, Jansen D, Van Beek M, Mutsaers MPC, et al. Resting-state functional connectivity changes in aging apoE4 and apoE-KO mice. J Neurosci (2014) 34:13963-75. doi:10.1523/JNEUROSCI. 0684-14.2014

74. Wiesmann M, Zerbi V, Jansen D, Haast R, Lütjohann D, Broersen LM, et al. A dietary treatment improves cerebral blood flow and brain connectivity in aging apoE4 mice. Neural Plast (2016) 2016:1-15. doi:10.1155/2016/ 6846721

75. Squillace M, Dodero L, Federici M, Migliarini S, Errico F, Napolitano F, et al. Dysfunctional dopaminergic neurotransmission in asocial BTBR mice. Transl Psychiatry (2014) 4:e427. doi:10.1038/tp.2014.69

76. Harris NG, Verley DR, Gutman BA, Thompson PM, Yeh HJ, Brown JA. Disconnection and hyper-connectivity underlie reorganization after TBI: a rodent functional connectomic analysis. Exp Neurol (2015) 277:124-38. doi:10.1016/j.expneurol.2015.12.020

77. Tehranian R, Rose ME, Vagni V, Griffith RP, Wu S, Maits S, et al. Transgenic mice that overexpress the anti-apoptotic Bcl-2 protein have improved histological outcome but unchanged behavioral outcome after traumatic brain injury. Brain Res (2006) 1101:126-35. doi:10.1016/j.brainres.2006.05.049

78. Zhang D, Raichle ME. Disease and the brain's dark energy. Nat Rev Neurol (2010) 6:15-28. doi:10.1038/nrneurol.2009.198

79. Logothetis NK. What we can do and what we cannot do with fMRI. Nature (2008) 453:869-78. doi:10.1038/nature06976

80. Hiltunen T, Kantola J, Abou Elseoud A, Lepola P, Suominen K, Starck T, et al. Infra-slow EEG fluctuations are correlated with resting-state network dynamics in fMRI. J Neurosci (2014) 34:356-62. doi:10.1523/JNEUROSCI. 0276-13.2014

81. Hughes JR. Gamma, fast, and ultrafast waves of the brain: their relationships with epilepsy and behavior. Epilepsy Behav (2008) 13:25-31. doi:10.1016/j. yebeh.2008.01.011

82. Feinberg DA, Yacoub E. The rapid development of high speed, resolution and precision in fMRI. Neuroimage (2012) 62:720-5. doi:10.1016/j. neuroimage.2012.01.049

83. Hutchison RM, Womelsdorf T, Gati JS, Leung LS, Menon RS, Everling S. Resting-state connectivity identifies distinct functional networks in macaque cingulate cortex. Cereb Cortex (2012) 22:1294-308. doi:10.1093/cercor/ bhr181

84. Choi EY, Yeo BTT, Buckner RL. The organization of the human striatum estimated by intrinsic functional connectivity. J Neurophysiol (2012) 108:2242-63. doi:10.1152/jn.00270.2012

85. Van Essen DC, Ugurbil K, Auerbach E, Barch D, Behrens TEJ, Bucholz R, et al. The Human Connectome Project: a data acquisition perspective. Neuroimage (2012) 62:2222-31. doi:10.1016/j.neuroimage.2012.02.018

86. Marcus DS, Harms MP, Snyder AZ, Jenkinson M, Wilson JA, Glasser MF, et al. Human Connectome Project informatics: quality control, database services, and data visualization. Neuroimage (2013) 80:202-19. doi:10.1016/j. neuroimage.2013.05.077
87. Gorges M, Müller H-P, Ludolph AC, Rasche V, Kassubek J. Intrinsic functional connectivity networks in healthy elderly subjects: a multiparametric approach with structural connectivity analysis. Biomed Res Int (2014) 2014:947252. doi:10.1155/2014/947252

88. Hutchison RM, Gallivan JP, Culham JC, Gati JS, Menon RS, Everling S. Functional connectivity of the frontal eye fields in humans and macaque monkeys investigated with resting-state fMRI. J Neurophysiol (2012) 107:2463-74. doi:10.1152/jn.00891.2011

89. Lemieux L, Salek-Haddadi A, Lund TE, Laufs H, Carmichael D. Modelling large motion events in fMRI studies of patients with epilepsy. Magn Reson Imaging (2007) 25:894-901. doi:10.1016/j.mri.2007.03.009

90. Müller H-P, Kassubek J. Multimodal imaging in neurology: special focus on MRI applications and MEG. Synth Lect Biomed Eng (2007) 2:1-75. doi:10.2200/S00099ED1V01Y200710BME016

91. Power JD, Mitra A, Laumann TO, Snyder AZ, Schlaggar BL, Petersen SE. Methods to detect, characterize, and remove motion artifact in resting state fMRI. Neuroimage (2014) 84:320-41. doi:10.1016/j.neuroimage.2013. 08.048

92. Ashby FG. Statistical Analysis of fMRI Data. Cambridge, MA: MIT Press (2011).

93. Friman O, Borga M, Lundberg P, Knutsson H. Detection and detrending in fMRI data analysis. Neuroimage (2004) 22:645-55. doi:10.1016/j.neuroimage. 2004.01.033

94. Song XW, Dong ZY, Long XY, Li SF, Zuo XN, Zhu CZ, et al. REST: a toolkit for resting-state functional magnetic resonance imaging data processing. PLoS One (2011) 6(9):e25031. doi:10.1371/journal.pone.0025031

95. Satterthwaite TD, Elliott MA, Gerraty RT, Ruparel K, Loughead J, Calkins ME, et al. An improved framework for confound regression and filtering for control of motion artifact in the preprocessing of resting-state functional connectivity data. Neuroimage (2013) 64:240-56. doi:10.1016/j.neuroimage. 2012.08.052

96. Caballero-Gaudes C, Reynolds RC. Methods for cleaning the BOLD fMRI signal. Neuroimage (2016). doi:10.1016/j.neuroimage.2016.12.018

97. Becerra L, Bishop J, Barmettler G, Kainz V, Burstein R, Borsook D. Brain network alterations in the inflammatory soup animal model of migraine. Brain Res (2017) 1660:36-46. doi:10.1016/j.brainres.2017.02.001

98. Chan RW, Ho LC, Zhou IY, Gao PP, Chan KC, Wu EX. Structural and functional brain remodeling during pregnancy with diffusion tensor MRI and resting-state functional MRI. PLoS One (2015) 10:e0144328. doi:10.1371/ journal.pone. 0144328

99. Westphal R, Simmons C, Mesquita MB, Wood TC, Williams SCR, Vernon AC, et al. Characterization of the resting-state brain network topology in the 6-hydroxydopamine rat model of Parkinson's disease. PLoS One (2017) 12:e0172394. doi:10.1371/journal.pone.0172394

100. Van Essen DC. Cartography and connectomes. Neuron (2013) 80:775-90. doi:10.1016/j.neuron.2013.10.027

101. Brett M, Johnsrude IS, Owen AM. The problem of functional localization in the human brain. Nat Rev Neurosci (2002) 3:243-9. doi:10.1038/nrn756

102. Ashburner J. A fast diffeomorphic image registration algorithm. Neuroimage (2007) 38:95-113. doi:10.1016/j.neuroimage.2007.07.007

103. Sunkin SM, Ng L, Lau C, Dolbeare T, Gilbert TL, Thompson CL, et al. Allen brain atlas: an integrated spatio-temporal portal for exploring the central nervous system. Nucleic Acids Res (2013) 41:D996-1008. doi:10.1093/nar/ gks1042

104. Oh SW, Harris JA, Ng L, Winslow B, Cain N, Mihalas S, et al. A mesoscale connectome of the mouse brain. Nature (2014) 508:207-14. doi:10.1038/ nature 13186

105. Sporns O, Bullmore ET. From connections to function: the mouse brain connectome atlas. Cell (2014) 157:773-5. doi:10.1016/j.cell.2014.04.023

106. Schwarz AJ, Danckaert A, Reese T, Gozzi A, Paxinos G, Watson C, et al. A stereotaxic MRI template set for the rat brain with tissue class distribution maps and co-registered anatomical atlas: application to pharmacological MRI. Neuroimage (2006) 32:538-50. doi:10.1016/j.neuroimage.2006.04.214

107. Ashburner J, Friston KJ. Voxel-based morphometry-the methods. Neuroimage (2000) 11:805-21. doi:10.1006/nimg.2000.0582

108. Müller H-P, Unrath A, Ludolph AC, Kassubek J. Preservation of diffusion tensor properties during spatial normalization by use of tensor imaging and 
fibre tracking on a normal brain database. Phys Med Biol (2007) 52:N99-109. doi:10.1088/0031-9155/52/6/N01

109. Holmes CJ, Hoge R, Collins L, Woods R, Toga AW, Evans AC. Enhancement of MR images using registration for signal averaging. J Comput Assist Tomogr (1998) 22:324-33. doi:10.1097/00004728-199803000-00032

110. Müller H-P, Unrath A, Riecker A, Pinkhardt EH, Ludolph AC, Kassubek J. Intersubject variability in the analysis of diffusion tensor images at the group level: fractional anisotropy mapping and fiber tracking techniques. Magn Reson Imaging (2009) 27:324-34. doi:10.1016/j.mri.2008.07.003

111. Whitwell JL. Voxel-based morphometry: an automated technique for assessing structural changes in the brain. J Neurosci (2009) 29:9661-4. doi:10.1523/ JNEUROSCI.2160-09.2009

112. Müller H-P, Vernikouskaya I, Ludolph AC, Kassubek J, Rasche V. Fast diffusion tensor magnetic resonance imaging of the mouse brain at ultrahigh-field: aiming at cohort studies. PLoS One (2012) 7:e53389. doi:10.1371/ journal.pone. 0053389

113. Shen X, Tokoglu F, Papademetris X, Constable RT. Groupwise whole-brain parcellation from resting-state fMRI data for network node identification. Neuroimage (2013) 82:403-15. doi:10.1016/j.neuroimage.2013.05.081

114. Beckmann CF, Smith SM. Probabilistic independent component analysis for functional magnetic resonance imaging. IEEE Trans Med Imaging (2004) 23:137-52. doi:10.1109/TMI.2003.822821

115. Beckmann CF, DeLuca M, Devlin JT, Smith SM. Investigations into restingstate connectivity using independent component analysis. Philos Trans $R$ Soc Lond B Biol Sci (2005) 360:1001-13. doi:10.1098/rstb.2005.1634

116. Valencia M, Pastor MA, Fernandez-Seara M, Artieda J, Martinerie J, Chavez M. Modular Organization as a Basis for the Functional Integration/Segregation in Large-Scale Brain Networks (2009). arXiv:0901.1605. Available from: https:// arxiv.org/abs/0901.1605

117. Shen X, Papademetris X, Constable RT. Graph-theory based parcellation of functional subunits in the brain from resting-state fMRI data. Neuroimage (2010) 50:1027-35. doi:10.1016/j.neuroimage.2009.12.119

118. Bastos AM, Schoffelen J-M. A tutorial review of functional connectivity analysis methods and their interpretational pitfalls. Front Syst Neurosci (2015) 9:175. doi:10.3389/fnsys.2015.00175

119. Cole DM, Smith SM, Beckmann CF. Advances and pitfalls in the analysis and interpretation of resting-state FMRI data. Front Syst Neurosci (2010) 4:8. doi:10.3389/fnsys.2010.00008

120. Sporns O. Structure and function of complex brain networks. Dialogues Clin Neurosci (2013) 15(3):247-62.

121. Bullmore E, Sporns O. Complex brain networks: graph theoretical analysis of structural and functional systems. Nat Rev Neurosci (2009) 10:186-98. doi:10.1038/nrn2575

122. van den Heuvel MP, Sporns O. Network hubs in the human brain. Trends Cogn Sci (2013) 17:683-96. doi:10.1016/j.tics.2013.09.012

123. van den Heuvel MP, Sporns O. Rich-club organization of the human connectome. J Neurosci (2011) 31:15775-86. doi:10.1523/JNEUROSCI.353911.2011

124. Rubinov M, Sporns O. Complex network measures of brain connectivity: uses and interpretations. Neuroimage (2010) 52:1059-69. doi:10.1016/j. neuroimage.2009.10.003

125. Ortiz A, Munilla J, Álvarez-Illán I, Górriz JM, Ramírez J; Alzheimer’s Disease Neuroimaging Initiative. Exploratory graphical models of functional and structural connectivity patterns for Alzheimer's disease diagnosis. Front Comput Neurosci (2015) 9:132. doi:10.3389/fncom.2015.00132

126. Munilla J, Ortiz A, Górriz JM, Ramírez J; Alzheimer’s Disease Neuroimaging Initiative. Construction and analysis of weighted brain networks from SICE for the study of Alzheimer's disease. Front Neuroinform (2017) 11:19. doi:10.3389/fninf.2017.00019

127. Ortiz A, Gorriz JM, Ramirez J, Salas-Gonzalez D. Improving MR brain image segmentation using self-organising maps and entropy-gradient clustering. Inf Sci (2014) 262:117-36. doi:10.1016/j.ins.2013.10.002

128. Ortiz A, Martínez-Murcia FJ, García-Tarifa MJ, Lozano F, Górriz JM, Ramírez J. Automated diagnosis of parkinsonian syndromes by deep sparse filtering-based features. In: Chen YW, Tanaka S, Howlett R, Jain L, editors. Innovation in Medicine and Healthcare 2016. Smart Innovation, Systems and Technologies. (Vol. 60), Cham: Springer (2016). p. 249-58.
129. Silva AC, Liu JV, Hirano Y, Leoni RF, Merkle H, Mackel JB, et al. Longitudinal functional magnetic resonance imaging in animal models. Methods Mol Biol (2011) 711:281-302. doi:10.1007/978-1-61737-992-5_14

130. Deco G, Jirsa VK, McIntosh AR. Resting brains never rest: computational insights into potential cognitive architectures. Trends Neurosci (2013) 36:268-74. doi:10.1016/j.tins.2013.03.001

131. Hillary FG, Roman CA, Venkatesan U, Rajtmajer SM, Bajo R, Castellanos ND. Hyperconnectivity is a fundamental response to neurological disruption. Neuropsychology (2014) 29:59-75. doi:10.1037/neu0000110

132. Buckner RL, Snyder AZ, Shannon BJ, LaRossa G, Sachs R, Fotenos AF, et al. Molecular, structural, and functional characterization of Alzheimer's disease: evidence for a relationship between default activity, amyloid, and memory. J Neurosci (2005) 25:7709-17. doi:10.1523/JNEUROSCI.2177-05. 2005

133. Douaud G, Filippini N, Knight S, Talbot K, Turner MR. Integration of structural and functional magnetic resonance imaging in amyotrophic lateral sclerosis. Brain (2011) 134:3470-9. doi:10.1093/brain/awr279

134. Gorges M, Müller H-P, Lulé D, Ludolph AC, Pinkhardt EH, Kassubek J. Functional connectivity within the default mode network is associated with saccadic accuracy in Parkinson's disease: a resting-state FMRI and videooculographic study. Brain Connect (2013) 3:265-72. doi:10.1089/brain. 2013.0146

135. Gorges M, Müller HP, Lulé D; LANDSCAPE Consortium, Pinkhardt EH, Ludolph AC, et al. To rise and to fall: functional connectivity in cognitively normal and cognitively impaired patients with Parkinson's disease. Neurobiol Aging (2015) 36:1727-35. doi:10.1016/j.neurobiolaging.2014.12.026

136. Mevel K, Chételat G, Eustache F, Desgranges B. The default mode network in healthy aging and Alzheimer's disease. Int JAlzheimers Dis (2011) 2011:535816. doi:10.4061/2011/535816

137. Schulthess I, Gorges M, Müller H-P, Lulé D, Del Tredici K, Ludolph AC, et al. Functional connectivity changes resemble patterns of pTDP-43 pathology in amyotrophic lateral sclerosis. Sci Rep (2016) 6:38391. doi:10.1038/ srep38391

138. Baliki MN, Chang PC, Baria AT, Centeno MV, Apkarian AV. Resting-sate functional reorganization of the rat limbic system following neuropathic injury. Sci Rep (2014) 4:6186. doi:10.1038/srep06186

139. Mishra AM, Bai X, Motelow JE, DeSalvo MN, Danielson N, Sanganahalli BG, et al. Increased resting functional connectivity in spike-wave epilepsy in WAG/Rij rats. Epilepsia (2013) 54:1214-22. doi:10.1111/epi.12227

140. Menke RAL, Proudfoot M, Wuu J, Andersen PM, Talbot K, Benatar M, et al. Increased functional connectivity common to symptomatic amyotrophic lateral sclerosis and those at genetic risk. J Neurol Neurosurg Psychiatry (2016) 87:580-8. doi:10.1136/jnnp-2015-311945

141. Petri G, Expert P, Turkheimer F, Carhart-Harris R, Nutt D, Hellyer PJ, et al. Homological scaffolds of brain functional networks. J R Soc Interface (2014) 11:20140873. doi:10.1098/rsif.2014.0873

142. Fornito A, Zalesky A, Breakspear M. Graph analysis of the human connectome: promise, progress, and pitfalls. Neuroimage (2013) 80:426-44. doi:10.1016/j.neuroimage.2013.04.087

143. Gass N, Becker R, Schwarz AJ, Weber-Fahr W, Clemm von Hohenberg C, Vollmayr B, et al. Brain network reorganization differs in response to stress in rats genetically predisposed to depression and stress-resilient rats. Transl Psychiatry (2016) 6:e970. doi:10.1038/tp.2016.233

144. Power JD, Schlaggar BL, Petersen SE. Studying brain organization via spontaneous fMRI signal. Neuron (2014) 84:681-96. doi:10.1016/j.neuron. 2014.09.007

145. Glasser MF, Sotiropoulos SN, Wilson JA, Coalson TS, Fischl B, Andersson $\mathrm{JL}$, et al. The minimal preprocessing pipelines for the Human Connectome Project. Neuroimage (2013) 80:105-24. doi:10.1016/j.neuroimage.2013. 04.127

146. Logothetis NK, Wandell BA. Interpreting the BOLD signal. Annu Rev Physiol (2004) 66:735-69. doi:10.1146/annurev.physiol.66.082602.092845

147. Burgess GC, Kandala S, Nolan D, Laumann TO, Power JD, Adeyemo B, et al. Evaluation of denoising strategies to address motion-correlated artifacts in resting-state functional magnetic resonance imaging data from the human connectome project. Brain Connect (2016) 6:669-80. doi:10.1089/brain. 2016.0435 
148. Garrison KA, Scheinost D, Finn ES, Shen X, Constable RT. The (in)stability of functional brain network measures across thresholds. Neuroimage (2015) 118:651-61. doi:10.1016/j.neuroimage.2015.05.046

149. Finn ES, Shen X, Scheinost D, Rosenberg MD, Huang J, Chun MM, et al. Functional connectome fingerprinting: identifying individuals using patterns of brain connectivity. Nat Neurosci (2015) 18:1664-71. doi:10.1038/ nn. 4135

150. Zingg B, Hintiryan H, Gou L, Song MY, Bay M, Bienkowski MS, et al. Neural networks of the mouse neocortex. Cell (2014) 156:1096-111. doi:10.1016/j. cell.2014.02.023

151. Hintiryan H, Foster NN, Bowman I, Bay M, Song MY, Gou L, et al. The mouse cortico-striatal projectome. Nat Neurosci (2016) 19:1100-14. doi:10.1038/ nn. 4332

152. Ghanem A, Conzelmann K-K. G gene-deficient single-round rabies viruses for neuronal circuit analysis. Virus Res (2016) 216:41-54. doi:10.1016/j. virusres.2015.05.023
153. Wertz A, Trenholm S, Yonehara K, Hillier D, Raics Z, Leinweber M, et al. Single-cell-initiated monosynaptic tracing reveals layer-specific cortical network modules. Science (2015) 349:70-4. doi:10.1126/science.aab1687

Conflict of Interest Statement: The authors declare that the research was conducted in the absence of any commercial or financial relationships that could be construed as a potential conflict of interest.

Copyright (C) 2017 Gorges, Roselli, Müller, Ludolph, Rasche and Kassubek. This is an open-access article distributed under the terms of the Creative Commons Attribution License (CC BY). The use, distribution or reproduction in other forums is permitted, provided the original author(s) or licensor are credited and that the original publication in this journal is cited, in accordance with accepted academic practice. No use, distribution or reproduction is permitted which does not comply with these terms. 